\title{
Results of cytological and microbiological examination using tracheal aspiration in race horses with lower respiratory tract disease
}

\author{
Sevim Kasap ${ }^{1}$, Engin Kennerman ${ }^{1}$, Huban Gocmen², Huseyin Cihan ${ }^{1}$, Mihriban Ulgen ${ }^{3}$ \\ ${ }^{1}$ Uludag University, Faculty of Veterinary Medicine, Department of Internal Medicine, Bursa, Turkey \\ ${ }^{2}$ Near East University, Faculty of Veterinary Medicine, Department of Microbiology, Nicosia, \\ Northern Cyprus, Turkey \\ ${ }^{3}$ Uludag University, Faculty of Veterinary Medicine, Department of Microbiology, Bursa, Turkey
}

Received December 18, 2016

Accepted December 7, 2018

\begin{abstract}
Respiratory tract disease is the second most common cause of poor performance in racehorses after musculoskeletal disease. Lower respiratory tract disorders (LRTD) are common in thoroughbred horses of all ages. The aim of this study was to investigate whether there was any association between the microbiological and cytological examinations. Fifty horses ranging in age from 2 to 6 years were examined. Horses with only upper respiratory tract abnormalities identified by endoscopy (at rest) were eliminated from the study and horses with LRTD were used in this study. Tracheal aspirate specimens were collected for cytological and microbiological examinations. Thirty six horses had positive and 14 horses had negative cultivation. The isolated bacteria included $\beta$-haemolytic Streptococcus equi subsp. zooepidemicus (38.8\%), Escherichia coli $(22.2 \%)$ and other bacteria that were isolated at rates ranging from 0.4 to $1.8 \%$. Percentages of neutrophils, lymphocytes, eosinophils, macrophages and mast cells were evaluated in the cytological examination. The percentages of neutrophils were significantly higher in the samples with isolated bacteria $(35.75 \pm 2.60 \%)$ compared to the samples from which bacteria were not isolated $(16.79 \pm 2.36 \%)(P<0.001)$. This study shows that $S$. equi subsp. zooepidemicus could play an important role in the etiopathogenesis of LRTD. It also demonstrates the importance of evaluating the microbiological findings of the tracheal aspirate specimens from horses suffering from respiratory infections, in addition to performing a detailed clinical examination and other complementary tests that focus on the respiratory system, such as endoscopy and cytology of the tracheal aspiration.
\end{abstract}

Equine, endoscopy, infection, Streptococcus, neutrophils

Respiratory tract disease is the second most common cause of poor performance in racehorses after musculoskeletal disease (Pascoe et al. 1981; Raphel et al. 1982). Lower respiratory tract disorders (LRTD) are common in thoroughbred horses of all ages. Although the presenting signs and symptoms vary with these disorders, they may include exercise intolerance, cough, nasal discharge, fever, respiratory distress, increased respiratory rate of effort, or generalized depression, inappetence, and weight loss. Amongst respiratory tract diseases, LRTD and the inflammatory airway disease have been discussed as common causes of poor performance, interruption of training and premature retirement in racehorses (Couetil et al. 2007). Careful clinical examination includes auscultation, and rebreathing often confirms the anatomic site of the problem.

Diagnostic testing, such as endoscopic examination, bronchoalveolar lavage, tracheal aspiration and wash with endoscopy, thoracic ultrasound, or thoracic radiography, are often indicated to confirm a suspected diagnosis (Davis et al. 2007).

Fibre optic endoscopy is an essential tool used to assess the equine respiratory tract. Endoscopic examination allows direct visualization of the upper respiratory tract, guttural pouches, trachea, and mainstem bronchi. Indications for endoscopic examination include

Address for correspondence:

Sevim Kasap

Department of Internal Medicine

Faculty of Veterinary Medicine

Uludag University, 16059, Bursa, Turkey

Phone: (+90 0224) 2940814

E-mail: cetins@uludag.edu.tr

http://actavet.vfu.cz/ 
upper airway noise, inspiratory difficulty, poor exercise performance, and unilateral or bilateral nasal discharge (Hodgson and Hodgson 2003).

Tracheal washing is a diagnostic procedure used in equine practice for respiratory disease because tracheal aspirates (TA) can provide clinicians with important cytological and microbiological information (Chapman et al. 2000; Takizawa et al. 2005). Bronchoalveolar lavage (BAL) is another diagnostic procedure for respiratory disease in horses, and cytological, biochemical and microbiological examinations of BAL fluid (BALF) provide even more accurate information to assist with the diagnosis of pneumonia (Hobo et al. 1997; Ito et al. 2001). Takizawa et al. (2005) suggested that the diagnostic value of TA obtained using endoscopes from young horses immediately after transportation is high for cytological examinations but extremely low with respect to bacteriological examination. According to these previous studies, BALF may provide more precise information than TA when diagnosing pneumonia in horses (Ode et al. 2007). However, some authors favoured TA because it is easier and cheaper to obtain, they believe that the sample contains secretions and cells originating from all areas of the lung (McGorum et al. 1994) and they can collect it free of outside contamination for bacteriological examination (Christley et al. 1999; Darien et al. 1990).

Normally, the trachea and bronchi (airways) contain small numbers of bacteria that are considered to be transient contaminants in the process of being removed by clearance mechanisms. When the pulmonary defence mechanism is overwhelmed, aspirated bacteria from the oropharynx may proliferate and cause pneumonia. The most commonly involved gram-positive bacteria are Streptococcus equi subsp. zooepidemicus ( $\beta$ - haemolytic) (Chapman et al. 2000; Christley et al 2001; Newton et al. 2003), Staphylococcus aureus and Streptococcus pneumoniae ( $\alpha$-haemolytic) (Chapman et al. 2000; Christley et al 2001). The most frequent gram-negative isolates are Pasteurella, Actinobacillus spp. (Chapman et al. 2000; Christley et al 2001; Newton et al. 2003), Escherichia coli (Debroy et al. 2008; Racklyeft and Love 2000), Klebsiella pneumoniae, Bordetella bronchiseptica (Davis et al 2007), and Enterobacter spp. (Sweeney et al. 1991).

In this study, we performed cytological and microbiological examinations using tracheal aspiration in 50 racehorses with LRTD. We also investigated whether there was any association between the microbiological and cytological examinations.

\section{Animals}

\section{Materials and Methods}

A total of 19 Arabic and 31 thoroughbred horses (total 50) ranging from 2 to 6 years of age were examined. Horses with only upper respiratory tract abnormalities that were identified by endoscopy were eliminated from the study and only horses with upper and LRTD were included. All horses were presented with a cough, nasal discharge and poor performance, and they were either in race training or racing. The physical examination, which included cardiac and thoracic auscultation, was normal in all cases, as was the lameness examination. All applications were performed under the control and approval of the University of Uludag Ethics Committee, in accordance with the Animal Welfare Guidelines (2009-10/06).

\section{Clinical examination}

Fifty racehorses demonstrated strong lower respiratory tract abnormalities. A weighted clinical score was provided for each subject, based on information from the history, physical examination, and endoscopic findings in the upper and lower airways at rest (Doucet and Viel 2002). The minimum clinical score was 5 (Table 1).

Endoscopic examination and tracheal aspirate cytology

Tracheal aspirates were obtained from 50 horses at the early stage of LRTD. The horses were restrained in the stocks, and a twitch was applied to the upper lip. A $3 \mathrm{~m}$ flexible endoscope (VetVu ${ }^{\circledR}$ VFS300, The Veterinarian's Endoscope, USA) was passed through one nostril to the pharynx and through the rima glottidis into the trachea. The endoscope was advanced through the straight mid-cervical trachea until the curvature of the distal trachea was observed. A single lumen polypropylene catheter tip was positioned just proximal to the tracheal bifurcation, and $50 \mathrm{ml}$ of sterile $0.9 \%$ saline was injected into the tracheal lumen; as much fluid as possible was aspirated under endoscopic visualisation. Samples were submitted to the laboratory and processed within 30 min of collection. 
Table 1. Case history, physical examination, and endoscopic evaluation used to calculate the clinical score of the lower respiratory tract.

\begin{tabular}{lcc}
\hline \multicolumn{1}{c}{ Case history } & Absent & Present \\
Poor performance (reported by trainer) & 0 & 1 \\
\hline Nasal discharge/coughing & & \\
or other related respiratory signs & 0 & 3 \\
Epistaxis & 0 & 1 \\
Inappetence, weakness & 0 & 1 \\
\multicolumn{1}{c}{ Physical examination } & & \\
\hline Temperature $>38^{\circ} \mathrm{C} \quad$ & 0 & 1 \\
Respiratory rate $>16 /$ dk & 0 & 1 \\
Nasal discharge & 0 & 3 \\
Abdominal effort at rest & 0 & 1 \\
Abnormal lung sounds on auscultation & 0 & 2 \\
Other problems on physical examination & 0 & 1 \\
$\quad$ Endoscopic evaluation & & \\
\hline Haemorrhage & 0 & 1 \\
Other upper airway disorders & 0 & 2 \\
Hyperaemia of the airways & 0 & 3 \\
Mucoid discharge & 0 & 1 \\
Purulent discharge & 0 & 3 \\
Oedema & 0 & 1 \\
\hline
\end{tabular}

Smears made from cytocentrifuged aliquots from samples were stained with Diff-Quik ${ }^{\circledR}$ (Baxter, Illinois) and of 100 inflammatory cells were counted. Cells in the specimens were classified into neutrophils, macrophages, lymphocytes, eosinophils and mast cells.

\section{Bacteriologic examination}

Tracheal aspirate sample from each horse was examined bacteriologically. The samples were preserved without disruption of the cooling chain and transmitted to the Microbiology Laboratory at the Faculty of Veterinary Medicine, Uludag University. For bacterial isolation, a $10 \mathrm{ml}$ aliquot of TA was centrifuged for $10 \mathrm{~min}$ at $2000 \times \mathrm{g}$. They were inoculated to general, selective and differential media for bacteriological isolation. Columbia agar with 5\% sheep blood, tryptic soy agar as general media, MacConkey agar, eosin methylene blue agar as differential agars and ceftazidime-novobiocin Mueller-Hinton agar, chocolate agar, and Edward's agar as selective media were used. All media were incubated both aerobically and anaerobically at $37^{\circ} \mathrm{C}$ for 24-48 h. The selective media were incubated for up to 5 days and controlled daily.

Bacterial identification of pure cultures was performed with routine methods (colony morphology, haemolysis characteristics, microscopy morphology, Gram staining and catalase, coagulase, and oxidase tests as some of biochemical tests) and API systems (API rapid ID 32 Strep, API Staph, API 20E, BioMerieux Industry, Italy).

\section{Statistical analysis}

The comparison of cytological examination between the samples with positive bacteriology and the samples without isolated bacteria was analysed via independent sample $t$-test. All the statistical analyses were performed using SPSS 13.0 (SPSS, Inc., Chicago, IL, USA). Results were expressed as mean \pm standard error and $P$ value $<0.05$ was considered as significant.

\section{Results}

\section{Clinical findings}

The respiratory rate was over $10-16$ breaths per min, and the body temperature was over $37.6-38.0^{\circ} \mathrm{C}$. Cough and nasal discharge were present in most cases. Nine horses had no cough, and hardened vesicular sound was present in 7 horses.

\section{Cytological findings}

The percentage of macrophages and neutrophils was $51.46 \%$ and $30.40 \%$, respectively, in the cytological results of TA (Table 3). The percentage of neutrophils and macrophages was $35.75 \%$ and $47.06 \%$, respectively, in samples with positive bacterial culture whereas the percentage of neutrophils and macrophages was $16.79 \%$ and $60.79 \%$, respectively, in TAs with negative bacterial culture (Table 3). The percentages of neutrophils were significantly higher in the samples with isolated bacteria compared with samples without positive cultivation $(P<0.001)$.

\section{Bacteriological findings}

A positive bacterial culture of TA was found in 36 of 50 horses. Fourteen bacterial species, including facultative aerobic organisms, gram-positive bacteria and six additional 
Table 3. Cytological findings in the tracheal aspirates obtained from racehorses with lower respiratory tract disease.

\begin{tabular}{lccr}
\hline Leukocyte cells & $\begin{array}{c}\text { Mean value in bacterial } \\
\text { isolated cases }(\mathrm{n}=36) \pm \mathrm{SE}^{*}\end{array}$ & $\begin{array}{c}\text { Mean value in non-bacterial } \\
\text { isolated cases }(\mathrm{n}=14) \pm \mathrm{SE}^{*}\end{array}$ & $\begin{array}{c}\text { General } \\
(\mathrm{n}=50) \pm \mathrm{SE}^{*}\end{array}$ \\
\hline Neutrophil (\%) & $35.75 \pm 2.60^{* * *}$ & $16.79 \pm 2.36$ & $30.40 \pm 2.31$ \\
Lymphocte (\%) & $15.08 \pm 1.17^{* *}$ & $21.50 \pm 2.14$ & $16.84 \pm 1.10$ \\
Eosinophil (\%) & $1.94 \pm 0.45$ & $1.57 \pm 0.30$ & $0.80 \pm 0.20$ \\
Macrophage (\%) & $47.06 \pm 2.22^{* * *}$ & $60.79 \pm 2.82$ & $51.46 \pm 1.95$ \\
Mast (\%) & $4.33 \pm 2.23$ & $1.00 \pm 0.00$ & $0.26 \pm 0.16$ \\
\hline
\end{tabular}

*SE: standard error

Difference of leukocyte cells percentage between bacterial isolated cases and non-bacterial isolated cases $(* * P<0.05$ and $* * * P<0.001)$.

species of gram-negative bacteria, including facultative anaerobic and aerobic bacteria, were isolated (Table 2). $\beta$-haemolytic $S$. equi subsp. zooepidemicus predominated (38.8\%), followed by E. coli $(22.2 \%)$. Other bacteria were isolated at rates ranging from 0.4 to $1.8 \%$.

Table 2. Bacterial isolation from the tracheal aspiration fluid obtained from racehorses with lower respiratory diseases.

\begin{tabular}{|c|c|}
\hline Aerobic/FA* bacteria & $\begin{array}{c}\text { Number } \\
\text { of bacteria (n) }\end{array}$ \\
\hline \multicolumn{2}{|l|}{ Aerobic/FA Gram+ cocci } \\
\hline Streptococcus equi subsp. zooepidemicus & 14 \\
\hline$\alpha$-haemolytic Streptococcus spp. & 5 \\
\hline \multicolumn{2}{|l|}{$\alpha$-haemolytic } \\
\hline Streptococcus dysgalactiae ssp. equisimilis & 1 \\
\hline$\alpha$-haemolytic Streptococcus uberis & 1 \\
\hline Staphylococcus sp. & 1 \\
\hline Staphylococcus lentus & 4 \\
\hline Staphylococcus gallinarum & 1 \\
\hline Staphylococcus equorum & 1 \\
\hline Staphylococcus sciuri & 1 \\
\hline Staphylococcus vitulus & 1 \\
\hline Staphylococcus haemolyticus & 2 \\
\hline Staphylococcus xylosus & 1 \\
\hline Staphylococcus saprophyticus & 1 \\
\hline$\beta$-haemolytic Streptococcus pyogenes & 1 \\
\hline \multicolumn{2}{|l|}{ Aerobic/FA Gram- bacilli } \\
\hline E. coli & 8 \\
\hline Enterobacter aerogenes & 2 \\
\hline Enterobacter cloacae & 3 \\
\hline Klebsiella pneumoniae ssp. pneumoniae & 1 \\
\hline \multicolumn{2}{|l|}{ Stenotrophomonas maltophilia } \\
\hline (Pseudomonas maltophilia) & 1 \\
\hline Shewanella putrefaciens & 1 \\
\hline Total number of bacteria & 51 \\
\hline
\end{tabular}

*FA: facultative anaerobic

\section{Discussion}

Poor performances and cough are among the most frequently symptoms reported (by owners, trainers or drivers) in association with LRTD (Laus et al. 2009). Laus et al. (2009) found that $64 \%$ of examined horses suffered from coughing, and reported coughing as a major clinical finding of LRTD. In this study, we found an even higher percentageof horses suffering from cough,namely $82 \%$ (41 out of 50 ). Coughing is known to be a relatively specific indicator of LRTD and a potential symptom of pneumonia, pleuritis,viral and bacterial respiratory infections, exerciseinduced pulmonary haemorrhage and chronic obstructive pulmonary disease (Bailey et al. 1999).

In equine practice, tracheal aspiration is a diagnostic procedure for LRTD because TA can provide clinicians with important cytological and microbiological information (Chapman et al. 2000). Tracheal aspiration can be easily performed through fibre optic endoscopy (Hodgson and Hodgson 2003; Santos et al. 2007). We performed 
the tracheal aspiration technique using fibre optic endoscopy in horses at the stable, without local anaesthesia.

Authors of a study of British racehorses indicated that $S$. zooepidemicus and $S$. pneumoniae play important aetiological roles in the pathogenesis of inflammatory airway disease in young horses and isolated aerobic bacteria such as E. coli, Enterobacter spp. and anaerobic bacteria such as Bacteriodes spp., and Clostridium spp. (Sweeney et al. 1991). However, $S$. pneumoniae was not isolated from TA in Japan (Newton and Wood 1999), which indicates that the presence of $S$. pneumonia can vary geographically. In this study, all TA samples were examined with bacteriological methods and aerobic and facultative anaerobic bacteria as pure and mixed culture were isolated. Streptococcus zooepidemicus $(27.4 \%)$ and E. coli $(15.6 \%)$ were isolated primarily from racehorses with LRTD. On the other hand, $\alpha$ - and $\beta$-haemolytic Streptococcus spp., coagulase negative Staphylococcus spp., K. pneumoniae, and Enterobacter spp. as aerobic/facultative anaerobic gram-negative bacteria were isolated from tracheal samples. These bacteria play mainly the role as opportunistic pathogens in LRTD. Bond et al. (2017) showed differentiation of lower respiratory tract microbiota between healthy and asthma horses. The genera Pseudomonas (14.57\%), Streptococcus (1.79\%) and Staphylococcus (3.6\%) belongong to the Firmicutes phylum were observed in healthy horses. However, they reported that the abundance of Streptococcus spp. was increased in horses with mild asthma. In this study, Streptoccocus species were the dominant bacteria that may be pathogenic or non-pathogenic in the lower respiratory tract and may cause the main disease or opportunistic infection in horses.

Several reports on LRTD suggest a relationship between respiratory organ inflammation and the bacteria isolated from TA specimens or between neutrophil and bacterial counts in TA specimens (Medica et al. 2010). According to Hodgson and Hodgson (2003), it is not possible to associate an increased number of neutrophils present in the tracheobronchial wash alone to a specific respiratory disease; it is necessary to link this information to other clinical and laboratory tests. According to Takizawa et al. (2005), cytological diagnosis of the tracheal aspirations revealed that observed cells were predominantly represented by neutrophils in 6 of 29 samples (samples with positive bacterial culture in the cytological examination). On the contrary, in the remaining 23 samples, most of the observed cells were pulmonary alveolar macrophages, epithelial cells, or lymphocytes, and neutrophils were rarely or not at all observed (samples with negative bacterial culture in the cytological examination). In this study, a number of different species of bacteria were isolated from 36 tracheal fluid samples. In a comparison between samples with and without bacteria, it appeared that there were differences in the numbers of inflammatory cells. The percentages of neutrophils were significantly higher in samples with positive bacterial culture $(P<0.001)$.

Several reports have suggested a relationship between cytological and clinical examinations (Beech 1975; Fernandes et al. 2011). Fernandes et al. (2011) have reported that TA cytology results showed decreased macrophages and increased neutrophils in response to a bacterial infection. In the same study, the cytological results showed a predominance of macrophages in the control group, with no clinical signs. Beech (1975) has reported that mononuclear cells were increased, according to a cytological examination of healthy horses. There was no control group in the present study, but the percentage of macrophages was higher in the horses with low clinical scores and no bacterial infections compared with the horses with bacterial infections. These results corresponded to the other studies. In this study, bacterial isolation was performed for 50 horses with clinical signs of LRTD; these horses also had higher clinical score compared to the others and 36 of them had positive cultivation. The percentages of neutrophils were significantly higher in the samples with isolated bacteria compared with samples without positive cultivation $(P<0.001)$. While an association between bacterial infection and lower airway inflammation 
has been described (Burrel et al. 1996), environmental exposure may also play a major role in this syndrome. Stabled horses can be exposed to very high levels of organic dust that contains a variety of mould and other components capable of inducing airway inflammation (Woods et al 1993; McGorum et al 1998). Authors of this study think that inadequate ventilation and shelter condition can lead to LRTD in horses without positive bacteriology. More detailed studies on this subject are planned.

In conclusion, many studies have emphasized the importance of cytological examination in racehorses in order to determine the cause of cough and decrease in sportive performance. Using the TA technique, airway samples can be obtained without difficulty, resulting in complete understanding of the airway status in horses. In addition, the results of the present study suggest the importance of evaluating the microbiological findings of TA samples in horses suffering from respiratory infections, along with performing a detailed clinical examination and other complementary tests that focus on the respiratory system, such as endoscopy and cytology of the TA. Thus, establishing a definitive diagnosis and the most appropriate therapy becomes feasible for LRTD.

\section{References}

Bailey CJ, Reid SWJ, Hodgson DR, Rose RJ 1999: Impact of injuries and disease on a cohort of two- and three-year-old thoroughbreds in training. Vet Rec 145: 487-493

Beech J 1975: Cytology of tracheabronchial aspirates in horses. Vet Path 12: 157-164

Bond SL, Timsit E, Workentine M, Alexander T, Leguillette R 2017: Upper and lower respiratory tract microbiota in horses: bacterial communities associated with health and mild asthma (inflammatory airway disease) and effects of dexamethasone. BMC Microbiology 17: 184

Burrel MH, Wood JL, Whitwell KE, Chanter N, Mackintosh ME, Munford JA 1996: Respiratory disease in thoroughbred horses in training: the relationships between disease and viruses, bacteria and environment. Vet Rec 139: 308-313

Chapman PS, Green C, Main JPM, Taylor PM, Cunningham FM, Cook AJC, Marr CM 2000: Retrospective study of the relationships between age, inflammation and the isolation of bacteria from the lower respiratory tract of thoroughbred horses. Vet Rec 146: 91-95

Christley RM, Hodgson DR, Rose RJ, Wood JLN, Reid SWJ, Whitear KG, Hodgson JL 2001: A case-control study of respiratory disease in thoroughbred racehorses in Sydney, Australia. Equine Vet J 33: 256-264

Couetil LL, Hoffman AM, Hodgson J, Buechner-Maxwell V, Viel L, Woods JL, Lavoie JP 2007: ACVIM Consensus Statement, Inflammatory airway disease of horses. J Vet Intern Med 21: 356-361

Davis EG, Freeman DE, Hardy J 2007: Respiratory infections. In: Sellon DC, Long MT (Eds): Equine Infectious Diseases. Saunders Elsevier, Philadelphia, pp. 1-7

Debroy C, Roberts E, Jayarao BM, Brooks JW 2008: Bronchopneumonia associated with extraintestinal pathogenic Escherichia coli in a horse. J Vet Diagn Invest 20: 661-664

Doucet MY, Viel L 2002: Clinical, radiographic, endoscopic, bronchoalveolar lavage and lung biopsy findings in horses with exercise-induced pulmonary hemorrhage. Can Vet J 43: 195-202

Fernandes WR, Sanches A, Ramos MCC, Souza VRC, Coelho CS 2011: Microbiological findings of tracheobronchial washes of healthy horses and those with respiratory diseases. Ars Veterinaria 27: 73-79

Hobo S, Oikawa M, Kuwano A, Yoshida K, Yoshihara T 1997: Effect of transportation on the composition of bronchoalveolar lavage fluid obtained from horses. Am J Vet Res 58: 531-534

Hodgson JL, Hodgson DR 2003: Tracheal Aspirates: Indications, Technique and Interpretation. In: Robinson NE (Ed.): Current Therapy in Equine Medicine, Saunders, St. Louis. pp. 401-406

Ito S, Hobo S, Eto D, Sato H 2001: Bronchoalveolar lavage for the diagnosis and treatment of pneumonia associated with transport in thoroughbred racehorses. J Vet Med Sci 63: 1263-1269

Laus F, Attili AR, Cerquetella M, Spaterna A, Tesei B, Cuteri V 2009: Endoscopic findings, microbiological and cytological evaluation of tracheal aspirates in a population of Standardbred horses with poor performances. Vet Med 54: 444-450

McGorum BC, Ellison J, Cullen RT 1998: Total and respirable airborne dust endotoxin concentrations in three equine management systems. Equine Vet J 30: 430-434

Medica P, Giacoppo E, Fazio E, Aveni F, Pellizzotto R, Ferlazzo A 2010: Cortisol and haematochemical variables of horses during a two day trekking event: effects of preliminary transport. Equine Vet J 38: 167-170

Newton JR, Wood JLN 1999: Summary of a case control study of acute respiratory disease in young Thoroughbred racehorses. In: Proceedings of British Equine Veterinary Association Congress, England 38: 190-191

Newton JR, Wood JL, Chanter N 2003: A case control study of factors and infections associated with clinically apparent respiratory disease in UK thoroughbred racehorses. Prev Vet Med 60: 107-132 
Ode H, Hobo S, Katayama Y, Niwa H, Kuwamoto Y, Yamane T, Anzai TJ 2007: Cytological and bacteriological observation of tracheal aspirates and bronchoalveolar lavage fluid obtained from thoroughbred racehorses with pneumonia associated with transport. Equine Sci 18: 161-165

Pascoe JR, Ferraro GL, Cannon JH, Arthur RM, Wheat JD 1981: Exercise induced pulmonary haemorrhage in racing thoroughbreds: a preliminary study. Am J Vet Res 42: 703-707

Racklyeft DJ, Love DN 2000: Bacterial infection of the lower respiratory tract in 34 horses. Aust Vet J 78: 549-559

Raphel CF 1982: Endoscopic findings in the upper respiratory tract of 479 horses. J Am Vet Med Assoc 181: 470-473

Santos LCP, Michelotto-Júnior PV, Kozemjakin DA 2007: Achados endoscópico e citológico das vias respiratórias de potros puro sangue inglês em início de treinamento no Jóquei Clube do Paraná (Respiratory endoscopic and cytological findings in English thoroughbred foals in the beginning of their training at Jóquei Club do Paraná). Arq Ciênc vet Zool UNIPAR 10: 9-13

Sweeney CR, Holcombe SJ, Barningham SC, Beech J 1991: Aerobic and anaerobic bacterial isolates from horses with pneumonia or pleuropneumonia and antimicrobial susceptibility patterns of the aerobes. J Am Vet Med Assoc 198: 839-842

Takizawa Y, Hobo S, Yamauchi J, Yamane T, Kuwamoto Y, Wada R, Anzai T 2005: Cytological and bacteriological observation of tracheobroncial aspirates from young thoroughbreds transported by vehicle over long distance. J Equine Sci 16: 117-121

Woods PS, Robinson NE, Swanson MC, Reed CE, Broadstone RV, Derksen FJ 1993: Airborne dust and aeroallergen concentration in a horse stable under two different management systems. Equine Vet J 25: 208-213 